\title{
Romances não criativos
}

\author{
Luciene Azevedo ${ }^{1}$
}

\begin{abstract}
El imitador o plagiario es un inocente abstemio de las comillas transcriptivas.
\end{abstract}

Macedonio Fernández

Cada vez tem se tornado mais comum autores contemporâneos referirem-se a suas próprias obras como um trabalho de curadoria. Em uma entrevista recente, Ben Lerner, autor americano que acaba de ter seu primeiro romance, Estação Atocha, traduzido para o português, diz isso com todas as letras: "Eu penso o romance como um tipo de curadoria" (2015). Afirmação muito semelhante foi feita por Cristiane Costa (2014a), autora de Sujeito oculto, livro que gostaria de comentar mais detidamente: "Vejo a autoria como uma curadoria". ${ }^{2}$

No entanto, o que significa pensar a escrita do romance como um ato de curadoria? Se pensarmos na figura do curador de arte, podemos imaginar que sua tarefa ao montar uma mostra ou cuidar de uma exposição diz respeito à organização de um corpus produzido por um artista cujo produto é a elaboração de uma narrativa sobre o próprio artista e sua obra. Cada vez mais, no universo das artes plásticas, a figura do curador tem se aproximado a de uma assinatura que implica uma renovação na maneira de apresentar o artista que é cuidado pelo olhar do curador.

Como isso poderia funcionar para a literatura? Kenneth Goldsmith, professor da universidade da Pensilvânia, tem defendido cada vez com maior veemência a ideia de que os "escritores estão se tornando curadores da linguagem e fazendo um movimento similar à emergência do curador como artista nas artes virtuais" (2015). Goldsmith ministrou durante alguns semestres um curso que ele mesmo chamou de "Escrita não criativa" e que consistia em estimular seus alunos a investigarem técnicas de apropriação de obras alheias. A escrita não criativa consiste, assim, em um procedimento de recortar e colar, uma espécie de sampling de obras diversas que derivam em um outro produto. Para Goldsmith,

\footnotetext{
${ }^{1}$ Doutora em literatura comparada e professora da Universidade Federal da Bahia (UFBA), Salvador, BA, Brasil. E-mail: aaluciene@gmail.com

${ }^{2} \mathrm{O}$ presente ensaio é um resultado parcial da pesquisa de pós-doutorado (2016-2017) financiada pela Fapesb-Capes.
} 
pensar a autoria como um processo curatorial é uma consequência direta do fato de vivermos em uma era digital. Segundo o autor, a internet obriga-nos a dedicar um tempo enorme para coletar e armazenar as informações que buscamos na rede e colocar à nossa disposição um arquivo de linguagem que possamos manejar com um simples controle das teclas CTRL-C/CTRL-V.

Identificando a monumental obra de Walter Benjamin, Das Passagenwerk, como a genealogia dessa transformação, o próprio Goldsmith acaba de publicar um livro que se apropria da ideia e dos procedimentos de construção da obra por Benjamin para escrever um projeto semelhante, agora sobre a cidade de Nova York. O livro consiste, então, em um conjunto de citações de trechos de romances, jornais, cartas e anúncios de propaganda sobre a cidade, entre muitas outras fontes, organizado sob diversas categorias, tais como as entradas benjaminianas que iam criando o labirinto de sua Paris do século XIX.

O que tanto a teoria quanto os projetos não criativos de Goldsmith sugerem é que, na fatura da própria escrita, há uma mostra do processo de criação em andamento, que é construído por meio do gesto de coletar, reunir, curar as passagens, como se o método da anotação, da apropriação de outros autores fosse suficiente como obra, tal como acontece no textoconstelação de Benjamin e no projeto de Goldsmith, por tabela. O que é tão fascinante no projeto de Benjamin? Para Goldsmith é a oportunidade de ler suas escolhas de leitura e se dar conta de que "muito poucas palavras foram escritas pelo próprio Benjamin" (2011). ${ }^{3}$

O processo de curadoria para Goldsmith consiste, então, em uma prática da apropriação e implica contestar a originalidade autoral. Sua escrita não criativa considera estranho que um autor "prefira agir como gênio original em vez de um gênio não original" (Goldsmith, 2015, s.p., tradução nossa).

Aqui, Goldsmith está fazendo uma alusão ao livro de Marjorie Perloff, lançado em 2010, cujo título é $O$ gênio não original. O pressuposto básico de Perloff no ensaio homônimo ao livro é que "as práticas atuais da arte têm o seu próprio momento e inventio particulares" (2013, p. 54) e que, em virtude dessa atualização, uma nova inventio, um novo conjunto de pressupostos caracterizadores de práticas artísticas, estaria em operação hoje. Mas o que

3 "No mínimo 75\% [de todas as palavras da obra] são transcrições diretas dos textos" (Sieburth apud Goldsmith, 2011, p. 113). 
é um gênio não original? Propondo uma espécie de recenseamento a fim de rastrear um paideuma possível, Perloff parte da estética da citação de Eliot em The Waste Land, passeia pelos experimentos dos oulipianos, do grupo Language e dos poetas concretos para defender a ideia de uma poesia conceitual, uma "poética da falta de originalidade"(2013, p. 42), caracterizada pela primazia dos procedimentos de apropriação: "a citacionalidade - com sua dialética de remoção e enxerto, disjunção e conjunção, sua interpenetração de origem e destruição - é central para a poética do século 21" (2013, p. 48).

Reconhecendo que a literatura - e mais especificamente a poesia resiste a práticas que há décadas impregnam as artes visuais, Perloff relaciona a não originalidade às práticas da citação, da cópia, da reprodução e da colagem, identificando aí a possibilidade de um novo paradigma para a criação literária. O pressuposto não defende, então, que "não haja um gênio em jogo" (2013, p. 54), mas que a noção de originalidade não pode mais ser relacionada a ele de forma tautológica uma vez que a inventio do século XXI supõe que ser original significa desenvolver as habilidades de "isolar, reconfigurar, reciclar, regurgitar, reproduzindo ideias e imagens que não são suas", tal como defende Goldsmith (2011, p. 139, tradução nossa). A autoria configurase, então, como um processo sintetizador, e não mais criador. Tal como o idealizador da Ubu Web, Perloff afirma que a prática da apropriação, mesmo sendo tão antiga quanto a própria arte, merece uma tentativa de singularização no contexto das práticas artísticas contemporâneas, especialmente pela importância que as novas tecnologias digitais assumem em nosso cotidiano.

Contudo, não é tão fácil assim para os fruidores da cultura literária do século XX acreditarem na falta de originalidade, nos termos propostos por Perloff e Goldsmith. Não só porque, como a própria Perloff reconhece, a história da arte tem uma longa tradição na prática da apropriação, mas talvez porque estejamos ainda sob o influxo do dictum kantiano. No parágrafo 46 de sua Crítica da faculdade do juízo, o filósofo afirma peremptoriamente: "Gênio é o talento (dom natural) que dá regra à arte". É bem verdade também que, após o decreto, por Barthes, da morte do autor, a categoria do gênio não tem lá muito crédito, principalmente passados mais de 200 anos de seu surgimento, quando muita discussão teórica já se ocupou do tema. Apesar da distância que mantemos em relação ao horizonte kantiano ao tratar do gênio, não é possível escamotear como 
nossos pressupostos valorativos, quando se trata dos produtos artísticos, ainda hoje estão associados, com maior ou menor sutileza, a um campo semântico que se aproxima de noções tais como criatividade ou originalidade. Quando Kant afirma que o juízo sobre a arte não pode ser deduzido de qualquer regra que tenha um conceito como fundamento está abrindo caminho para a primazia do gênio sobre sua criação, identificandoo a "um talento para produzir aquilo para o qual não se pode fornecer nenhuma regra determinada" (1995, p. 153). E a afirmação de que a "originalidade tem de ser sua primeira propriedade" é a outra face do interdito para a arte como instituição: "o gênio opõe-se totalmente ao espírito de imitação" (1995, p. 154).

É possível pensar, então, que a sugestão de Perloff para a inventio do século XXI, cuja força está na capacidade de manipular formas já existentes operando sobre elas, apropriando-se delas para recriá-las, está na prática da curadoria que os autores contemporâneos parecem exercitar em relação às suas próprias obras?

Vamos aos exemplos.

Pensar a composição do romance como uma curadoria parece ser um procedimento plausível para as narrativas que investem na exposição de si e que aproximam o autor do narrador. As autoficções contemporâneas operam a técnica da seleção e combinação ou do recortar e colar das memórias e ficções do sujeito que se conta. Na literatura brasileira recente, ninguém investiu tanto na autoficção como Ricardo Lísias. Mas, na prática desse gênero, o que me interessa realçar é o procedimento recursivo de elaboração consciente da obra que constitui uma marca de autoria de Lísias. Afinal, a estratégia de samplear os temas, distribuindoos por publicações que antecipam as narrativas mais longas - como acontece, por exemplo com $O$ céu dos suicidas -, é reconhecido pelo próprio Lísias: "cheguei inclusive a publicar alguns testes, alguns textos preparatórios a ele (ao romance)" (2012). Construindo sua obra como uma espécie de coleção de séries que se intercambiam, Lísias explora a repetição de situações narrativas, que funcionam como um esboço prévio do que o leitor encontrará nas narrativas de maior fôlego: a adoção da corrida como novo hobby, que também funciona como metáfora da escrita como recuperação de um trauma, está presente em um conto publicado na Revista Piauí e reaparece no romance Divórcio; a repetição expandida das circunstâncias do fim do casamento, da descoberta do diário, já presentes em "Meus três Marcelos"; bem como a menção ao suicídio do 
amigo André, que é um mote que já vinha sendo disseminado há algum tempo por ficções publicadas esparsamente. Esse recortar e colar a si mesmo, a sua própria obra, pode implicar uma curadoria estratégica das apropriações, que oferecem ao leitor simultaneamente a repetição e a diferença. Lísias poderia, então, estar escrevendo não criativamente, para retomar a nomenclatura utilizada por Perloff e Goldsmith, ao repropor textos preexistentes em novas obras. Nesse sentido, o reaproveitamento de seus próprios motes, a repetição de si, implicaria uma curadoria, um cuidado na elaboração da performance narrativa.

Deixando de lado, agora, o território das escritas de si, há quem prefira o "êxtase da influência". A expressão de Jonathan Lethem, logo percebemos, é uma brincadeira com a ideia da angústia da influência de Harold Bloom. Em ensaio publicado na Revista Serrote, Lethem defende que "a apropriação, a imitação, a citação, a alusão e a colaboração sublimada consistem em uma espécie sine qua non do ato criativo, permeando todas as formas e gêneros no campo da produção cultural" (2012, p. 121), e que esse é um procedimento típico da estética do século XXI.

Alguns autores da literatura brasileira recente têm investido nessa prática, incorporando a apropriação como parte do processo de construção de suas obras. Tomemos o exemplo de $O$ gato diz adeus, de Michel Laub (2009). Depois da leitura, encontramos ao final do livro uma nota ao leitor: o conto citado por um personagem é de David Foster Wallace; uma passagem reproduz exemplos de "O demônio do meiodia", de Andrew Solomon, e "Em sua temática, linguagem e estrutura, é possível que esse romance deva algo a Enquanto agonizo, de William Faulkner, A caixa preta, de Amós Oz, e A chave, de Junichiro Tanizaki" (Laub, 2009, p. 78). Resenhando o livro, Adriano Schwarz foi impiedoso. Citando um verso de Drummond ("a plástica é vã, se não comove"), o crítico afirma que a nota exige que o leitor reavalie o romance depois de lê-lo, restando-lhe, então, duas opções: "interpretá-la como mais um dado do quebra-cabeça proposto pela narrativa e a partir daí tentar reenquadrar o romance (circunstância em que as apostas subiriam bastante, mas a chance de fracasso também) ou acreditar que o autor de fato toma a voz ali e informa para quem interessar as suas principais fontes" (Schwartz, 2009, s.p.). Avaliando que o romance de Laub perde valor e "não se mantém em pé" diante das referências que evoca, Schwarz não é muito tolerante com uma espécie de curadoria de leitura que parece estar em jogo no desejo do ficcionista de nomear suas influências de 
criação, pois aposta que, ao esclarecê-las ao leitor, Laub só faz realçar seu fracasso. Ao insistir em nomear suas apropriações, o autor quer registar um dívida, talvez evitar uma acusação de apropriação indébita e mostrar algo da fatura da composição do romance. Esse último aspecto parece o mais interessante para capitalizar a ideia de curadoria, pois ainda que a nota atue como uma forma de "inspiração" e como um paratexto, é por meio dela que temos acesso a um esboço do romance, a seu estado de preparação que começa na dieta de leituras do autor.

Mas se no romance de Laub a operação se parece mais à alusão ou à "colaboração sublimada" que evoca um paideuma de formação, no novo romance de Verônica Stigger, Opisanie Swiata, a operação de recortar e colar fica mais evidente. A prática da anotação, da curadoria de leitura é um procedimento estruturador da composição do romance. "Eu roubo demais, descaradamente. O escritor é um canibal que se apropria de tudo" (Stigger apud Moura, 2012).

Assim como na nota de Laub, encontramos ao final do romance de Stigger uma relação de nomes e obras, alguns relacionados ao modernismo brasileiro, mas também menções a conversas da autora com pessoas de seu círculo familiar, como Ivo Stigger e Ida Stigger (2013, p. 154), e literário, como Carlito Azevedo e Leandro Sarmatz. Nomeando essa lista como "deveres", Stigger estimula uma ambiguidade. Trata-se das dívidas intelectuais da autora com as pessoas e obras citadas, sem dúvida, mas a palavra lembra também uma tarefa, um dever, como uma lição de casa para a escrita do romance e, por tabela, uma lição de casa para o leitor. Mais do que a alusão ou homenagem à evocação dos autores admirados, como acontece no caso de Laub, no romance de Stigger, a lista implica um repertório de referências, temas, modos de vida que marcaram o modernismo brasileiro e que foi anotado meticulosamente para ser enxertado na narrativa. Ângela Maria Dias (2015) perseguiu a pista desses "deveres" e identificou que, ao longo do romance, há passagens inteiras copiadas de algumas das obras citadas na relação ao final do volume. Logo no início da narrativa, por exemplo, a descrição de Bopp é quase toda retirada do famoso ensaio sobre o autor escrito por Sérgio Buarque de Hollanda. As passagens "roubadas" integram o tecido narrativo do relato de Stigger sem se denunciarem, prescindindo das aspas. Para sua identificação é preciso recorrer às fontes (o que pode não ser tão difícil com a ajuda do Google), cotejar o "original" com a "cópia", ler os "deveres" como parte da estratégia narrativa do livro. É esse procedimento que 
parece sugerido pela seção ao final do livro. O que passamos a ler, então, não é apenas a história da viagem feita por Opalka ou seu encontro feliz com Raul Bopp e suas histórias, mas também uma espécie de arcabouço do romance dado a ver como o romance mesmo e que estende ao leitor o convite para refazer o caminho de montagem elaborado pela autora, compartilhando suas conversas casuais, as leituras da biblioteca modernista, que aparecem costuradas pela apropriação, pelo recorte e pela colagem de suas anotações, que se transformam em narrativa.

Embora Dias afirme que para ela "o interesse do relato reside, sobretudo, na prática do recorte e da colagem da citação" (2015, p. 65), a crítica também rejeita o procedimento, lamentando que não haja uma "clivagem entre enunciado e enunciação" (2015, p. 74). Com isso, Dias quer sugerir que a autora deixa de lado a acidez crítica da antropofagia modernista para ficar só na "estilização dos materiais", apostando todas as suas fichas no humor. Mas talvez o efeito de recorte e colagem provocado pela leitura da narrativa de Stigger não seja o mesmo previsto pela análise do trabalho de citação feita por Compagnon e tomado como referência por Dias. Segundo Dias, "Compagnon considera o processo de apropriação como um sintoma, no qual o objetivo do sujeito da enunciação seria menos tomar de outrem, que empreender uma busca de si" (2015, p. 66).

$\mathrm{O}$ que quero sugerir é que se a apropriação revela a imbricação entre a leitura e escrita, como os exemplos aqui citados demonstram, também é plausível pensar que remeta à ideia de preparação, esboço anotado para escrever. Nesse sentido, o uso da apropriação por Stigger não é mera peça de construção para sua própria voz, sua própria narrativa "original", mas sua criatividade ou originalidade está em compor uma lógica coral (Sussekind, 2013, s.p.), amalgamando-se a suas referências. Ou, como afirma Lethem, "encontrar uma dicção própria não é apenas esvaziar-se e purificar-se das palavras dos outros, mas adotar e acolher filiações, comunidades e discursos" (2012, p. 121) A reinvenção da criatividade significa propor a leitura como uma espécie de escrita, tal como parece propor o pacto de leitura da obra benjaminiana referida anteriormente. Ou ainda: entender o romance como um objeto de curadoria implica entendê-lo como um ato de leitura e anotação. Pelo contrário, é a incontornável presença das inúmeras vozes que compõem o romance que configura um convite ao compartilhamento de autorias, uma espécie de "autoria 
em condomínio" (Speranza, 2006, p. 99), que deixa ver ao mesmo tempo um esmaecimento da voz da própria Stigger e, em virtude dessa mesma operação de "escrita-através", ${ }^{4}$ uma voz autoral.

A ideia de forma coral, tal como comentada por Sussekind, parece fazer bastante sentido aqui. Pois na "operação de escuta", ouvimos uma "espécie de câmara de ecos na qual ressoa o rumor (à primeira vista inclassificável, simultâneo) de uma multiplicidade de vozes" (Sussekind, 2013, s.p.). Mas falar em romance não criativo e em autor não original parece evocar o campo semântico do plágio. Se fosse interesse dessa comunicação traçar uma genealogia dessa história, deveria fazer justiça aos argentinos e nomear a polêmica envolvendo Sergio Di Nucci (Bruno Morales) ou ainda o antológico empreendimento de Ricardo Piglia travestindo-se de Robert Arlt em Nome falso, mas, é claro, principalmente, Jorge Luis Borges e seu Pierre Menard como precursor dessa discussão, pois, nas palavras de John Barth, "Borges não atribui a si mesmo o Quixote e muito menos o reescreve como Pierre Menard. Escreve, sim, uma obra de literatura original e notável, cujo tema implícito é a dificuldade, talvez a falta de necessidade de escrever obras originais de literatura" (1984).

A "vocação parasitária que prevalece nas melhores ficções de Borges" (Pauls e Helft, 2000, p. 104, tradução nossa) incita a apropriação de forma manifesta. Mas, para Maria Kodama, viúva de Borges, essa prática não passa do bom e velho plágio. Foi por isso que iniciou um processo judicial contra a editora Alfaguara e contra o autor espanhol Agustín Fernández Mallo por ter escrito uma versão remake do livro El hacedor (de Borges) e mais recentemente conseguiu uma vitória contra o argentino Pablo Katchadjian por "fraude da propriedade intelectual", em função da publicação de 300 cópias independentes de El aleph engordado, que consiste em uma "expansão estilística", que aumenta a narrativa de Borges acrescentando-lhe palavras, mas mantendo intacto o conteúdo original.

Os defensores da escrita não criativa reinterpretam o plágio como uma "força operativa nova", para evocar a posição da crítica argentina Graciela Speranza (2006, p. 294). O que Kodama julga ser uma apropriação indébita da originalidade de Borges, Goldsmith vê como a aposta na criação de novos significados que repropõem textos

\footnotetext{
${ }^{4}$ A noção de "escrita-através" é mencionada por Perloff para descrever a operação de apropriação de elementos da cultura pop (filmes, quadrinhos, colunas de jornal), o que permite ao autor "participar de um discurso maior e mais público" (2013, p. 41).
} 
preexistentes. Para evocar um último exemplo, podemos dizer que Sujeito oculto, livro de Cristiane Costa (2014a), constitui uma boa oportunidade para discutir a permeabilidade das fronteiras entre $\mathrm{o}$ plágio e a reapropriação.

Diz Cristiane Costa: "Na escrita recreativa, o autor é editor, um curador, a partir da seleção de elementos e como ele coloca isso, se faz um novo projeto criativo. Esse é o meu trabalho" (2015). Mas o que acontece em Sujeito oculto? O livro é dividido em três capítulos. No primeiro, lemos uma espécie de depoimento de um marido ressentido com as circunstâncias da morte da mulher, desconfiando de um suicídio. Construído como narrador inconfiável, à maneira de D. Casmurro, não se sabe ao certo quanto há de encenação no desabafo que faz quando lamenta não ter conhecido de fato Alice, sua mulher, já que a preocupação ansiosa do narrador também pode ser creditada à contestação pela seguradora do pagamento do seguro de vida em virtude da dúvida sobre as circunstâncias da morte de sua esposa.

Carlos, então, passa a vasculhar com sofreguidão uma série de cadernos com anotações mantidos por Alice com trechos retirados das leituras que realizava. Logo no início, lemos o marido atordoado com o volume de anotações e marcações e destaques que Alice deixou nos livros de sua biblioteca: "O pior é que nem tenho certeza se ela copiou ou escreveu esse negócio por conta própria. Ela se disfarçava, eu sei. Só não sabia quanto" (2014a, p. 19). Somos introduzidos, então, paulatinamente, ao mote geral do livro: a apropriação. Diz Carlos: "[Alice] só conseguia falar com as palavras dos outros. Não foi à toa que não deixou obra nenhuma, só livros sublinhados e algumas frases e fragmentos soltos" (2014a, p. 58). E aos poucos o leitor se dá conta de que está lendo uma colcha de retalhos que amalgama inúmeras referências literárias: aparecem no relato do marido, que não é um leitor experto de literatura, os hábitos de Alice - que assim como Kafka, mantém um caderno azul no qual anotava sonhos - e a reprodução de inúmeros trechos destacados pela mulher. As fontes são ecléticas: versos de Bishop, como "A arte de perder não é difícil de aprender" (p. 29); trechos de romances de Ariel Dorfman, Fitzgerald, Rebecca West; lições retiradas de livros de autoajuda; trechos de correspondência entre outros. Aos poucos, o leitor vai entrando na rede sampleada das referências de leitura de Alice, que é mimetizada no relato do marido. 
É através de seu trabalho de edição que ficamos sabendo o que Alice "circulou-assinalou-copiou" (2014a, p. 19). Mas o livro parece dar uma guinada metalinguística a partir do segundo capítulo. Ali o leitor se depara com mais de 20 páginas cujas palavras aparecem tarjadas com tinta preta, impossibilitando a leitura. Só no terceiro capítulo, os termos do contrato de leitura parecem se estabelecer e estabilizar. Aí encontramos um texto "a título de posfácio", assinado pelo crítico Julio Paz, que fornece informações que tornam possível ao leitor redescrever sua experiência de leitura, pois ficamos sabendo que o que acabamos de ler é na verdade o livro escrito por Catarina Guerra. Não temos acesso ao segundo capítulo, pois a autora foi acusada de plágio e, desgostosa com a repercussão do episódio, decide afastar-se da carreira literária.

A guinada metalinguística não se explica apenas por recorrer ao velho mote do livro dentro do livro, mas porque a dicção crítica encontrada nesse posfácio repete o procedimento de recorte e colagem encontrado no primeiro capítulo como estratégia de composição do método de leitura e escrita de Alice. À medida que vamos lendo o capítulo-ensaio de Julio Paz, encontramos os tópicos de discussão mais recorrentes hoje da pauta crítica sobre literatura: a mescla entre a ficção e a vida, a intromissão da figura do autor em seu relato, a "cultura do copy and paste" e a vasta lista de casos de plágio que pulula no noticiário literário. Mas o mais interessante aqui é perceber a curadoria da própria Cristiane Costa em ação, pois na leitura somos capazes de identificar inúmeros cacoetes com que esbarramos quando lemos crítica sobre a literatura contemporânea.

Se no primeiro capítulo estávamos a mercê do olhar de Carlos sobre o comportamento de sua mulher, no capítulo de crítica, ficamos reféns da leitura do crítico, que alega não só ter tido acesso à primeira edição completa do livro de Catarina Guerra, sem a supressão do segundo capítulo, raríssima no mercado, como se vale da amizade pessoal e do acesso à correspondência eletrônica que manteve com a autora (e que é incorporada à sua resenha crítica) para dar plausibilidade à sua hipótese interpretativa. E qual é mesmo essa hipótese? Depois de ficarmos conhecendo com riqueza de detalhes a vida pessoal de Catarina (seu caso amoroso com o orientador de doutorado, suas conturbadas relações familiares, a suspeita, alentada pela autora, pelo menos na versão do crítico, de que seu pai foi o responsável pela morte de sua mãe), acompanhamos a hipótese crítica 
esmerando-se em comprovar uma explicação da obra, de sua personagem, espelhada na vida da autora: "basta observar como o drama familiar e a escrita de Catarina se entrelaçam", afirma o crítico com tranquilidade (2014a, p. 103). Embora cerque-se de cuidados para evitar determinismos (na linha do tal vida, tal obra), é nessa direção que a avaliação do crítico se aprofunda, aproximando a dicção crítica de uma trama romanesca: "A hipótese que lanço aqui é a de que a autora realizou um hábil bordado para dizer com todas as letras o que nunca teria audácia de afirmar publicamente: a mãe se matou e o pai era o grande culpado" (2014a, p. 111).

O título desse capítulo-posfácio parece desvendar a curadoria de Costa. "Frases feitas" cai como uma luva para ilustrar a sensação de dejà $v u$ que experimenta o leitor acostumado à leitura da crítica literária. Mas a ironia está no próprio procedimento de composição de que Costa lança mão, pois, ao identificarmos na dicção de Julio Paz inúmeros clichês do discurso crítico, damo-nos conta de que a questão estruturadora da narrativa, como forma e como tema, é a apropriação. Afinal, temos a impressão de que "as opiniões que compõem o texto" são anônimas, de atribuição impossível e, no entanto, já lidas, relidas; são citações sem aspas" (Lethem, 2012, p. 138).

$\mathrm{Na}$ condição de crítico especializado, Julio Paz parece ter pouca vantagem em relação a Carlos, pois as conclusões a que chega são muito semelhantes às do marido de Alice. Ambos são seduzidos pela pulsão de ler a obra, as anotações, pela vida. Mas enquanto Carlos acusa a falta de imaginação de Alice, condenando sua prática de anotação ("minha mulher podia até ter talento... mas não tinha imaginação. Se tivesse, teria escrito vários livros... em vez de roubar frases feitas" (2014, p. 67), o crítico valida a aposta de Catarina Guerra de falar com a voz dos outros, "escrever-através": "lanço a hipótese de que Sujeito oculto não seja exatamente um plágio, mas um livro sobre o plagiarismo, que radicaliza a questão da autoria, antecedendo discussões sobre apropriação, remix e mashup" (2014a, p 103).

Já quase no final do capítulo, que faz às vezes de ensaio crítico, podemos ler um e-mail pessoal de Catarina Guerra enviado a Julio Paz e tratado por este como um documento. Nessa correspondência, Catarina, a suposta autora do livro homônimo ao que temos nas mãos, cuja autoria é de Cristiane Costa, diz ter encontrado uma "caixa cheia de cadernos de frases feitas e trechos de poemas e romances" (p. 151), com a letra da mãe. 
Dai, afirma, nasce o desejo de escrever um romance "reciclando trechos, desapropriando palavras [...]. O trabalho maior era dar lógica e coerência a tudo, lixar e pintar por cima, para não chamar a atenção para o paciente trabalho de bricolagem" (p. 157).

O romance de Costa interessa ao meu argumento, então, porque parece uma máquina perfeita para pensar a apropriação como impulso de anotação. O conjunto das anotações (dos personagens do romance, mas também de Costa como estágio de elaboração para a fatura do livro) ganha corpo aqui porque a obra parece pensada a partir do método da recolha, da montagem que caracterizam o trabalho de curadoria. O romance é, assim, um inventário de anotações montado como um quebra-cabeças que oferece ao leitor a curadoria desse processo de construção levado a cabo pela autora e que constitui o próprio romance. Pensado como uma espécie de laboratório de construção, o romance e a própria ideia de autoria podem desfazem a oposição entre a originalidade e apropriação e redescrever o plágio como uma força operativa nova, funcionando como uma outra inventio para o século XXI.

\section{Referências}

BARTH, John (1984). The literature of exhaustion. In: BARTH, John. The friday book: essays and other non-fiction. London: The John Hopkins University Press.

COSTA, Cristiane (2014a). Sujeito oculto. Rio de Janeiro. Aeroplano.

COSTA, Cristiane (2014b). Em novo romance escritora usa plágio como recurso literário. Entrevista a Maurício Meirelles. O Globo, Rio de Janeiro, 27 nov. Disponível em: https://goo.gl/OZSJil. Acesso em: 4 out. 2015.

COSTA, Cristiane (2015). Curta! Com Cristiane Costa e Leonardo Villa-Forte. Vídeo. Disponível em: https://goo.gl/jrN2wT. Acesso em: 4 out. 2015.

DIAS, Ângela Maria (2015). A descrição do mundo de Verônica Stigger ou uma antropofagia desidratada. O Eixo e a Roda, Belo Horizonte, v. 24, n. 1, p. 61-76, jan./jul. Disponível em: https://goo.gl/3mZ2td. Acesso em: 9 set. 2016.

GOLDSMITH, Kenneth (2011). Uncreative writing. Managing language in the digital age. New York. Columbia University Press.

GOLDSMITH, Kenneth (2015). I look to theory only when I realize that somebody has dedicated their entire life to a question I have only fleetingly 
considered. The purposes of repurposing. Poetry!, Chicago, $1^{\text {st }}$ Apr. Disponivel em: https://goo.gl/v5eEhm. Acesso em: 4 out. 2015.

KANT, Immanuel (1995). Crítica da faculdade do juízo. Tradução de Valerio Rohden e Antonio Marques. 2. ed. Rio de Janeiro: Forense Universitária.

LAUB, Michel (2009). O gato diz adeus. São Paulo: Companhia das Letras.

LERNER, Ben (2014). Each cornflake. London Review of Books, London, v. 36, n. 10, 22 maio. Disponível em: https://goo.gl/oY4WQX. Acesso em: 4 out. 2015.

LERNER, Ben (2015). Time is a flat circle: Ben Lerner interviewed. The Quietus, London, 8 fev. Entrevista a Karl Smith. On-line. Disponível em: https://goo.gl/aooP0B. Acesso em: 4 out. 2015.

LETHEM, Jonathan (2012). O êxtase da influência: um plágio. Tradução de Alexandre Barbosa de Souza e Bruno Costa. Serrote, São Paulo, v. 12, p.117-147, nov.

LÍSIAS, Ricardo (2012). Entrevista ao Paiol Literário. Jornal Rascunho, Curitiba, n. 145 On-line. Disponível em: http://rascunho.com.br/ricardo-lisias/. Acesso em: 9 dez. 2012.

MOURA, Carolina (2012). Veronica Stigger fala das origens e das apropriações de sua literatura. Notícias do Dia, Florianópolis, 2 dez. On-line. Disponível em: https://goo.gl/Dl3VHO. Acesso em: 4 out. 2015.

PAULS, Alan; HELFT, Nicolas (2000). El factor Borges. Nueve ensayos ilustrados. Buenos Aires: Fondo de Cultura Económica.

PERLOFF, Marjorie (2013). O gênio não original. Poesia por outros meios no novo século. Belo Horizonte: Editora da UFMG.

SCHWARTZ, Adriano (2009). Muito cálculo enfraquece boa estrutura. Folha de S. Paulo, caderno Ilustrada, 25 abr. Disponível em: https://goo.gl/pty5IF. Acesso em: 9 set. 2016.

SPERANZA, Graciela (2006). Fuera de campo. Literatura y arte argentinos después de Duchamp. Barcelona: Anagrama.

STIGGER, Veronica (2013). Opisanie Swiata. São Paulo: Cosac Naify.

SUSSEKIND, Flora (2013). Objetos verbais não identificados. O Globo, Rio de Janeiro, caderno Prosa e Verso, 21 set. Disponível em: <http://goo.gl/18j8Hf>. Acesso em: 22 out. 2013

Recebido em janeiro de 2016.

Aprovado em maio de 2016. 


\section{resumo/abstract/resumen}

\section{Romances não criativos}

Luciene Azevedo

Se consideramos a extensa bibliografia teórica sobre o romance, não é possível deixar de reconhecer a instabilidade de sua forma como traço característico do gênero. Assim, gostaria de aproveitar o mote e discutir mais atentamente a hipótese de que alguns exemplos contemporâneos dão uma nova volta ao parafuso e sugerem novas maneiras de fabricar e consumir narrativas hoje, apontando, mais uma vez, para a remodelação das fronteiras do gênero romanesco. Minha reflexão, então, tem como fundamento teórico a noção de "escrita não criativa" tal como elaborada por Kenneth Goldsmith (2011) para pensar a prática da apropriação de outros textos posta em operação por algumas narrativas da literatura contemporânea brasileira, tais como Opsanie Swiata, de Verônica Stigger, ou Sujeito oculto, de Cristiane Costa, acreditando que tais formas provocam um redimensionamento valorativo da noção de obra, de originalidade e do próprio conceito de literatura.

Palavras-chave: escrita não criativa, romance, forma, Verônica Stigger, Cristiane Costa.

\section{Uncreative novels}

\section{Luciene Azevedo}

If one considers the extensive bibliography on the novel, it's impossible not to acknowledge that the instability of its form is a characteristic trait of the genre. I would like to take advantage of this element to discuss more thoroughly the hypothesis that some contemporary literary texts represent, so to speak, a new turn in the genre, suggesting innovative ways of both creating and consuming narratives nowadays, and indicating once more a refashioning of the genre's boundaries. My reflections take as their theoretical foundation the notion of "non-creative writing", as advanced by Kenneth Goldsmith (2011) that, I believe, lays the groundwork for a reflection about the practices of appropriation of other texts at play in some contemporary Brazilian narratives -- for instance, in Opsanie Swiata, by Verônica Stigger, and Sujeito oculto, by Cristiane Costa. The essay proposes that such refashioning provokes a redimensioning of the values we usually apply to the notions of literary work, of originality, and of the very concept of literature.

Keywords: non creative writing, novel, form, Verônica Stigger, Cristiane Costa. 


\section{Novelas no creativas}

Luciene Azevedo

Si tenemos en cuenta la amplia bibliografía teórica sobre la novela, no es posible dejar de reconocer la inestabilidad de su forma como rasgo característico del género. Para discutir la hipótesis de que algunos ejemplos contemporáneos dan otra vuelta de tuerca al tema y pueden sugerir nuevas maneras de fabricar y consumir narrativas hoy en día, remodelando las fronteras del género novelístico, la reflexión tiene como base la noción de "escritura no-creativa" de Kenneth Goldsmith (2011) y por tanto intenta pensar la práctica de la apropiación de otros textos como ocurre en algunas narrativas de la literatura contemporánea brasileña, tales como Opsanie Swiata, de Verônica Stigger, o Sujeito oculto, de Cristiane Costa. Tales textos crean una nueva dimensión para el entendimiento de la noción de obra, de la originalidad y del propio concepto de literatura.

Palabras clave: escritura no creativa, novela, forma, Verônica Stigger, Cristiane Costa. 